\title{
REMUNICIPALIZAÇ̃̃O E COPRODUÇÃO dO BEM PÚBLICO: PERSPECTIVAS DE GESTÃO dOS SEERVIÇOS DE ÁGUA E SANEAMENTO
}

\author{
Remunicipalization and Co-Production of Public Goods: Prospects for Water and Sanitation Services Management \\ Remunicipalización y Coproducción de Bienes Públicos: Perspectivas para la Gestión de Servicios de Agua y \\ Saneamiento
}

\section{RESUMO}

A população mundial ainda enfrenta grandes desafios para que os serviços de água e saneamento atendam a todos, principalmente nas áreas rurais. Frente a uma tendência mundial, esses serviços encontram-se em um marco histórico de remunicipalização. Nesse contexto, calha bem a discussão do tema sob a ótica da coprodução do bem público. 0 objetivo é analisar como o processo de remunicipalização de serviços de água e saneamento pode representar uma possibilidade para o desenvolvimento da coprodução do bem público. Para tanto, optou-se por uma investigação teórica a partir da literatura nacional e internacional sobre 0 tema. Ao final, apresentamos uma agenda de estudos e hipóteses de pesquisa para as relações entre os processos de remunicipalização dos serviços de água e saneamento e o desenvolvimento da coprodução do bem público.

PALAVRAS-CHAVE: gestão das águas, privatização, transparência, governança pública, participação social.

\section{Érica Aline Ferreira Silva Yamamoto'}

ferreiraerica@estudante.ufla.br

ORCID: https://orcid.org/0000-0002-1294-3087

José Roberto Pereira'

jrobertopereira2013@gmail.com

ORCID: http://orcid.org/0000-0003-1570-2016

Valderí de Castro Alcântara²

valderidecastroalcantara@gmail.com

ORCID: http://orcid.org/0000-0002-6698-0609

1. Universidade Federal de Lavras

2. Universidade do Estado de Minas Gerais - Unidade Cláudio

Submetido 02-09-2019. Aprovado 02-03-2020

Avaliado pelo processo de double blind review

DOI: http://dx.doi.org/10.12660/cgpc.v25n81.80080 
Érica Aline Ferreira Silva Yamamoto - José Roberto Pereira - Valderí de Castro Alcântara

\section{ABSTRACT}

The world's population still faces major challenges regarding water and sanitation services to serve everyone, especially in rural areas. Faced with a worldwide trend, these services are presented in a historical framework of remunicipalization. In this context, the discussion of the topic is well suited from the perspective of the co-production of the public good. The objective is to analyze how the processes of remunicipalization of water and sanitation services can represent a possibility for the development of co-production of the public good. Therefore, we opted for a theoretical investigation based on the national and international literature on the subject. Finally, we present an agenda of studies and research hypotheses for the relations between the remunicipalization processes of water and sanitation services and the development of the co-production of the public good.

KEYWORDS: water management, privatization, transparency, public governance, social participation.

\section{RESUMEN}

La población mundial todavía enfrenta grandes desafíos para que los servicios de agua y saneamiento sirvan a todos, especialmente en las zonas rurales. Ante una tendencia mundial, estos servicios están en un hito historico de remunicipalización. En este contexto, la discusión del tema está muy bajo la óptica de la coproducción del bien público. El objetivo es analizar cómo el proceso de remunicipalización de los servicios de agua y saneamiento puede representar una posibilidad para el desarrollo de la coproducción del bien público. Por lo tanto, se eligió una investigación teórica de la literatura nacional e internacional sobre los temas. Al final, presentamos una agenda de futuros estudios e hipótesis de investigación para las relaciones entre los procesos de remunicipalización de los servicios de agua y saneamiento y el desarrollo de la coproducción del bien público.

PALABRAS CLAVE: gestión del agua, privatización, transparencia, gobierno público, participación social.

\section{INTRODUÇÃO}

Água potável de qualidade, saneamento básico, saúde pública e boas condições de moradia são essenciais para a vida. A população mundial, equivalente a mais de 7,3 bilhões de pessoas, ainda enfrenta grandes desafios para que os serviços de água e saneamento atendam a todos, principalmente nas áreas rurais (World Health Organization \& The United Nations Children's Fund, 2017). Em relação à gestão, atualmente, os serviços de água e saneamento no mundo se encontram em um marco histórico de remunicipalização. O processo é caracterizado por serviços que há anos estiveram sob domínio de empresas privadas e retornam para o setor público (Lobina, 2015; Hachfeld, 2008). Este retorno ocorre por diferentes fatores que vão desde o encerramento de contratos, apenas, até a busca por menores tarifas, qualidade e transparência.
O fortalecimento do setor público e a representação social da água contribuem para a discussão da temática coprodução do bem público. Dessa forma, é preciso considerar que nenhum setor, seja ele público, privado ou público não governamental consegue gerir com eficiência e eficácia os recursos naturais. Segundo Age e Schommer (2017) "a coprodução é uma abordagem que potencialmente aumenta a qualidade, a eficiência e a legitimidade dos serviços públicos, podendo ser aplicada do planejamento à entrega do serviço" (p. 426). Para Salm (2014) "esses bens e serviços compreendem desde a formulação de políticas públicas e a articulação de movimentos que buscam o bem da comunidade, até a realização de serviços rotineiros de segurança, saúde, educação, entre outros" (p. 43).

De forma complementar, Lobina (2015) apresenta a remunicipalização como uma alter- 
nativa para melhorar os serviços públicos de água no âmbito da sua gestão e no melhor atendimento à sociedade. No entanto, do ponto de vista teórico ainda não foi discutido como a remunicipalização contribui para o desenvolvimento de arranjos de coprodução do bem público, em especial nos serviços de abastecimento de água. Diante disso, levanta-se o seguinte problema de pesquisa: Como o processo de remunicipalização dos serviços de água e saneamento pode representar uma possibilidade para o desenvolvimento da coprodução do bem público? Para contextualizar a temática, este artigo traz relatos de remunicipalização em casos brasileiros: os Estados de São Paulo e Tocantins apresentam registros de serviços de água que retornaram para o domínio público. Entretanto, o cenário atual da política nacional não está favorável à tendência e sinaliza para um processo de privatização, indo na contramão das perspectivas de vários outros países.

O objetivo é analisar como o processo de remunicipalização de serviços de água e saneamento pode representar uma possibilidade para o desenvolvimento da coprodução do bem público. Para tanto, optou-se por uma investigação teórica a partir da literatura nacional e internacional sobre os temas. Ao final, apresentamos uma agenda de estudos e hipóteses de pesquisa para as relações entre os processos de remunicipalização dos serviços de água e saneamento e o desenvolvimento da coprodução do bem público.

\section{CENÁRIO GLOBAL DO ACESSO À ÁGUA POTÁVEL E AO SANEAMENTO}

O Programa de Monitorização Conjunta da World Health Organization (WHO) e United Nations Children's Fund (UNICEF) para o abastecimento de água, saneamento e higiene divulgou o resultado de um amplo trabalho de estimativas regulares abrangendo os níveis nacional, regional e global sob a ótica de três pilares: água potável, saneamento e higiene desde 1990. O relatório Progress on Drinking Water, Sanitation and Hygiene publicado em 2017 apresenta o progresso do saneamento, da água e da higiene e estabelece novos desafios para que sejam, de fato, serviços universais (WHO \& UNICEF, 2017). Trata-se do instrumento mais abrangente - até o presente momento de publicação - com uma análise global que visa a atender, também, a agenda 2030.

A Agenda 2030 para o Desenvolvimento Sustentável foi divulgada em 2015 pela Organização das Nações Unidas (ONU), englobando os direitos humanos à água e ao saneamento seguro. São 17 objetivos de desenvolvimento sustentável e 169 metas que contemplam a Agenda 2030. Os objetivos e as metas são integrados e equilibram-se nas dimensões econômica, social e ambiental (ONU, 2015).

Especificamente o objetivo 6 trata de água potável e saneamento, a fim de assegurar uma gestão sustentável e acessível para todas e todos. Este objetivo é constituído por seis metas (Quadro 1). 
Quadro 1. Metas do Objetivo 6

6.1 Até 2030, alcançar o acesso universal e equitativo à água potável, segura e acessível para todos;

Até 2030, alcançar o acesso a saneamento e higiene adequados e equitativos para

6.2 todos, e acabar com a defecação a céu aberto, com especial atenção para as necessidades das mulheres e meninas e daqueles em situação de vulnerabilidade;

Até 2030, melhorar a qualidade da água, reduzindo a poluição, eliminando despejo e minimizando a liberação de produtos químicos e materiais perigosos, reduzindo à metade a proporção de águas residuais não tratadas, e aumentando substancialmente a reciclagem e reutilização segura globalmente;

Até 2030, aumentar substancialmente a eficiência do uso da água em todos os setores

6.4 e assegurar retiradas sustentáveis e o abastecimento de água doce para enfrentar a escassez de água, e reduzir substancialmente o número de pessoas que sofrem com a escassez de água;

Até 2030, implementar a gestão integrada dos recursos hídricos em todos os níveis, inclusive via cooperação transfronteiriça, conforme apropriado;

6.6 Até 2020, proteger e restaurar ecossistemas relacionados com a água, incluindo montanhas, florestas, zonas úmidas, rios, aquíferos e lagos;

Até 2030, ampliar a cooperação internacional e o apoio ao desenvolvimento de capacidades para os países em desenvolvimento em atividades e programas relacionados

6.a à água e ao saneamento, incluindo a coleta de água, a dessalinização, a eficiência no uso da água, o tratamento de efluentes, a reciclagem e as tecnologias de reuso; 6.b $\begin{aligned} & \text { Apoiar e fortalecer a participação das comunidades locais, para melhorar a gestão da } \\ & \text { água e do saneamento. }\end{aligned}$

Fonte: ONU (2015, p. 25-26).

Essas metas buscam ações para que, de fato, os serviços de água e saneamento sejam disponibilizados a toda a população mundial. Para o alcance, é necessário meIhorar a qualidade da água, uma vez que, embora muitas populações tenham acesso a ela, este não é de forma adequada; acabar com o despejo incorreto; e promover ações para eliminar a escassez desse bem. As metas articulam-se em prol de uma gestão integrada entre sociedade, Estado e mercado como forma de ampliar a cooperação e o apoio internacional aos programas relacionados à água e ao saneamento.
Esta gestão compartilhada promove o fortalecimento da participação social, a qual deve ser atuante na prestação de serviços de interesse público (ONU, 2015). Os objetivos globais contemplam o reconhecimento de cada população, respeitando suas origens, seus potenciais e, principalmente, suas limitações. $\mathrm{O}$ direito humano à água e aos serviços de saneamento deve ser de conhecimento amplo, bem como priorizado nas metas dos governos.

Segundo Connor, Uhlenbrook e Koncagül 
(2019), a água potável e os serviços de saneamento de forma segura são reconhecidos como direitos humanos básicos e indispensáveis para que o meio de subsistência seja saudável e digno a todos. Este reconhecimento ocorreu por meio da Assembleia Geral das Nações Unidas em 28 de julho de 2010, Resolução n. 64/292, que declarou água potável e saneamento básico como direitos humanos essenciais à vida (ONU, 2010).

Ao tratar a água enquanto um direito humano, compreende-se que deve ser um bem de atendimento universal, o que complementa o questionamento apresentado pelo The United Nations World Water Development Report, um relatório produzido pelo World Water Assessment Programme em nome da UN-Water em 2019: Quem está sendo deixado para trás? A pergunta emerge de um cenário global deficiente em muitos aspectos no que tange ao saneamento básico seguro e à água potável de qualidade.

Para Connor et al. (2019), essa discriminação tem uma série de motivos, mas a pobreza é um fator de destaque. Fatores sociais e culturais também contribuem para exclusão e discriminação. Picolli, Kligerman, Cohen, e Assumpção (2016) reforçam esta ideia ao dizer que os seres humanos situados em diferentes realidades influenciadas por diversas culturas possuem os mesmos direitos. Segundo as autoras, "observa-se que não há direito à água, se ela não for segura para consumo, o que só pode ser atingido com medidas sanitárias básicas" (Picolli et al., 2016, p. 798).

As condições de inúmeras regiões e a discriminação em populações menos favore- cidas não permitem que lei, regulamentos, políticas e práticas sejam universais em seu atendimento. Para que a população tenha acesso a serviços de qualidade, é necessário o oferecimento de instalações básicas de água potável e saneamento a fim de assegurar a saúde pública, a produtividade no trabalho, na escola, e o bem-estar social.

A realização dos direitos humanos à água e ao saneamento exige que os serviços sejam disponíveis, física e financeiramente acessíveis, seguros e culturalmente aceitáveis. "Não deixar ninguém para trás" está no coração do compromisso da Agenda 2030 para o Desenvolvimento Sustentável, que visa a permitir que todas as pessoas em todos os países se beneficiem do desenvolvimento socioeconômico e atinjam a plena realização dos direitos humanos (Connor et al., 2019, p. 2).

Este direito atribui obrigações legais aos Estados e aos órgãos responsáveis em relação à regulamentação de pagamentos pelos serviços, além de garantir o atendimento universal (Connor et al., 2019). Deste modo, Connor et al. (2019) afirmam que aspectos como a "inovação e disseminação tecnológica, o aperfeiçoamento da gestão por meio da boa governança, o aumento das práticas de transparência e a implementação de ações custo-efetivas podem melhorar a eficiência da produção e, com isso, reduzir os custos dos serviços" (p. 6). No entanto, água, saneamento e higiene são considerados um direito básico e, em tese, devem ser fornecidos independentemente de seu custo e/ou da capacidade de pagamento das pessoas (Connor et al., 2019).

É importante conhecer os deveres e as res- 
ponsabilidades que cabem a cada ator, seja ele representante do Estado, de Organizações Não Governamentais (ONGs), participantes ativos da sociedade, dentre outros. Segundo Connor et al. (2019), "os direitos humanos definem os indivíduos como titulares de direitos à água e ao saneamento e, da mesma forma, estabelecem responsáveis que têm o dever de garantir o acesso de todos à água, ao saneamento e à higiene, com o uso do máximo de seus recursos disponíveis" (p. 12). Para Picolli et al. (2016), ao pensar em maior participação da população na arena político-administrativa, há a necessidade de pensar também na descentralização deste espaço por meio de políticas públicas que reflitam preocupações que transformem o território local.

O primeiro passo para construir uma relação perene entre a Água e a humanidade é a superação da alienação da sociedade em relação à Água. A percepção de que para utilizar a Água basta abrir a torneira e pagar a conta posteriormente deve ser rompida. A sociedade civil necessita conscientizar que a captura, transporte e riscos envolvidos na governança hídrica formam o processo responsável pela disponibilidade hídrica da população e buscar corresponsabilidade das decisões estratégicas (Dowbor \& Rodrigues, 2017, p. 156).

O trabalho em prol da superação dessa alienação mencionada pelos autores reflete uma mudança de comportamento, concepções e paradigmas. Há aqueles que compartilham de uma visão da água enquanto "mercadoria" e consideram, segundo Dowbor e Rodrigues (2017), que a natureza é insumo do processo produtivo, fazendo deste bem um gerador de riquezas para as organizações até que o recurso seja esgotado e alcance o máximo de retorno investido possível. Entretanto, este estudo reconhece a água enquanto direito e não uma commodity.

Ressalta-se que 2,1 bilhões de pessoas não têm água potável em casa e, no que tange aos serviços de saneamento de forma segura, mais do dobro dessas pessoas também não dispõe (WHO \& UNICEF, 2017). Estes números são equivalentes a cerca de $3 \mathrm{em}$ cada 10 pessoas sem água potável em suas casas, e 6 em cada 10 que carecem de saneamento seguro. Na África Subsaariana está localizada quase a metade das pessoas que consomem água de fontes desprotegidas (WHO \& UNICEF, 2017; Connor et al., 2019).

Na população mundial, apenas 39\% utilizam os serviços de saneamento de forma segura; $27 \%$ dispõem de instalações de saneamento privadas que estão conectadas a esgotos tratados; $13 \%$ utilizam vasos sanitários ou latrinas para os excrementos; enquanto 892 milhões de pessoas em todo o mundo ainda praticam esta ação a céu aberto, dentre outros dados preocupantes que afetam diretamente a qualidade de vida das populações (WHO \& UNICEF, 2017).

Em relação à higiene, 70 países tiveram seus dados disponíveis em 2015 no quesito lavar as mãos com sabão, o que representa $30 \%$ do total da população. Na África Subsaariana, $15 \%$ possuem instalações para a lavagem das mãos com sabão comparado a $76 \%$ da Ásia Ocidental e África do Norte. No entanto, os dados disponíveis são insuficientes para produzir uma estimativa global. 
Em geral, tem-se que, entre 2000 e 2015, o número de pessoas que praticaram defecação ao ar livre teve uma redução média de 22 milhões de pessoas por ano (WHO \& UNICEF, 2017).

Diante dessa breve discussão do cenário global, a gestão de recursos hídricos apresenta mudanças em relação à origem dos serviços. Durante muitos anos, grandes empresas dominaram o setor de saneamento no mundo. No entanto, por razões econômicas, políticas, sociais e ambientais esses serviços estão retornando para o controle público. A remunicipalização pode contribuir para o fortalecimento das relações entre a gestão local e a população, promovendo melhorias no atendimento.

\section{REMUNICIPALIZAÇÃO}

Ao analisar tendências mundiais nos serviços de água, Lobina (2015) destaca que cidades, regiões e países em todo o mundo optam por cada vez mais fecharem as relações à privatização, tomando de volta a prestação dos serviços de água em um processo denominado remunicipalização. Para Lobina (2015), falar de remunicipalização é tratar de algo recente, emergente e que não poderia ser previsto. Mas trata-se de um fator marcante capaz de redesenhar o setor de água e saneamento mundialmente.

Busca-se, então, definir e esclarecer alguns pontos envolvendo a compreensão do processo de remunicipalização.

Remunicipalisation refers to the return of previously privatised water supply and sanitation services to public service delivery. More precisely, remunicipalisation is the passage of water services from privatisation in any of its various forms - including private ownership of assets, outsourcing of services, and public-private partnerships (PPPs) - to full public ownership, management and democratic control. Indeed, concessions, lease contracts, other PPPs, and water privatisation are one and the same thing: all these terms refer to the transfer of management control to the private sector, at various degrees. Water privatisation and PPPs are equally problematic, and their problems are deep-seated. This explains why remunicipalisation typically occurs after local governments terminate unsatisfactory private contracts or do not renew them after expiry (Lobina, 2015, p. 7).

A ressalva feita pelo autor descreve e caracteriza a volta dos serviços para o domínio público. Lobina (2015) esclarece que o processo de remunicipalização não acontece, necessariamente, na esfera municipal, podendo alcançar um contexto mais amplo.

Hachfeld (2008) retrata algumas lutas globais pela apropriação social da água frente a uma tendência de privatização desses serviços. O autor destaca que isso ainda não acabou e que há uma significativa oposição à privatização caracterizada por mobilizações políticas e sociais. Essas mobilizações não só conseguiram parar os planos de privatização, como foram bem-sucedidas em recuperar água privatizada de volta para domínio público em alguns casos.

Como panorama dessa temática, Lobina e Hall (2013) desenvolveram um estudo que apresenta uma lista de remunicipalizações no mundo. O intuito principal dos autores é 
mostrar que os casos ocorridos nos últimos 15 anos em países desenvolvidos e em transição aconteceram a partir de três razões: problemas gerais que afetam a privatização da água, independentemente do país e/ou do regime regulatório; eficiência igual ou maior dos serviços públicos de água, juntamente com preços mais baixos resultantes da eliminação de lucros excessivos; e vantagem comparativa do setor público tanto ao creditar o direito humano à água e ao saneamento, como em alcançar outros objetivos sociais e ambientais (Lobina \& Hall, 2013).

Kishimoto, Lobina, e Petitjean (2015) relatam acerca de 235 casos de remunicipali- zação no período de 2000 e 2015, incluindo experiências em países-chave, como França, Estados Unidos e Alemanha, e em grandes capitais globais, como Paris, Berlim e Jacarta. O processo de remunicipalização apresentou um crescimento significativo, tornando-se uma prática, principalmente nos países desenvolvidos.

Observa-se que o país mais representativo é a França, com 94 casos de remunicipalização, seguido dos Estados Unidos, com 58, e Espanha, com 14. Além desses países, tem-se Alemanha, com 9 casos, Argentina, com 8 , dentre outros espalhados pelo mundo ( $\mathrm{Fi}$ gura 1).

Figura 1. Remunicipalização no mundo

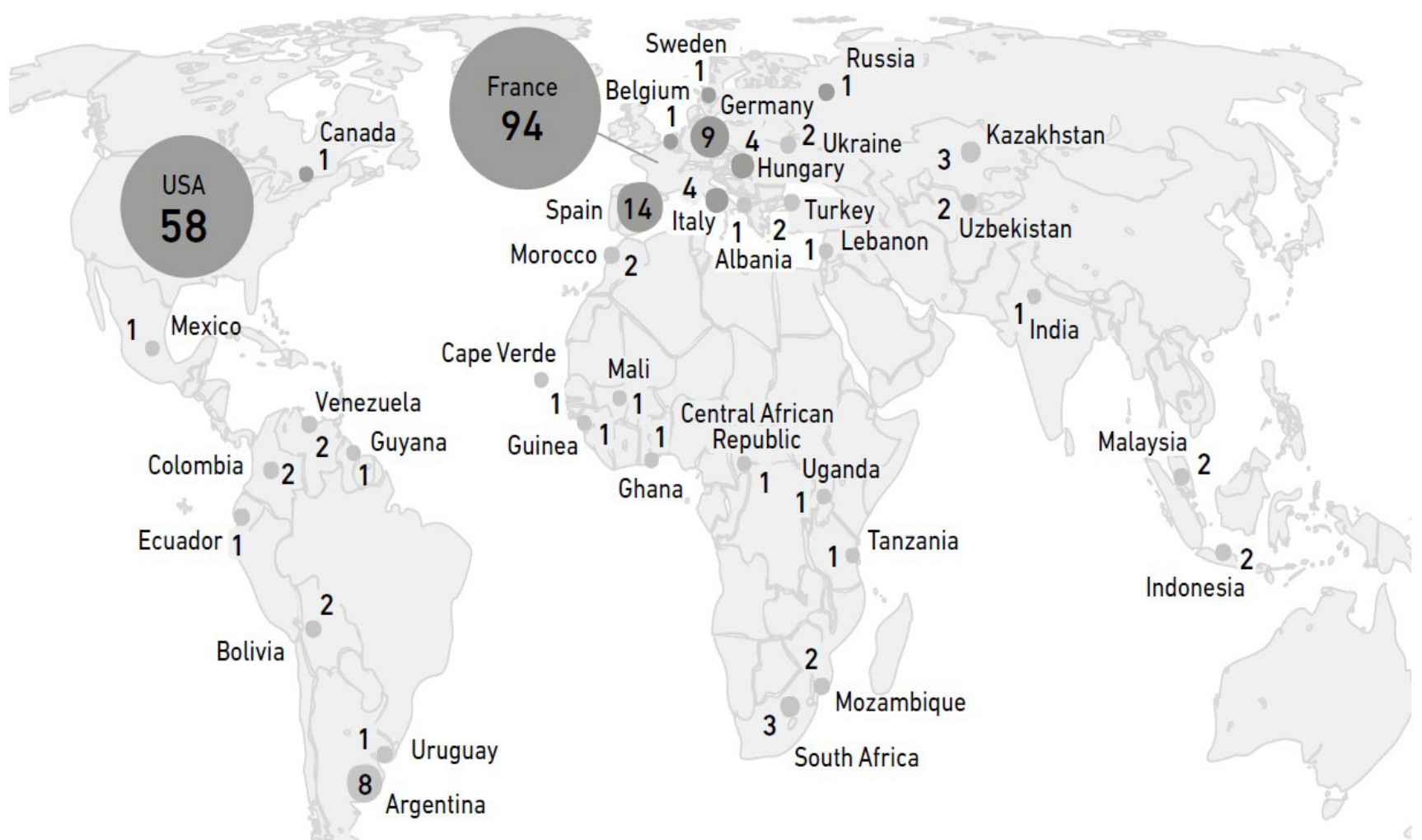

Sources: PSIRU, France Eau Publique, Food \& Water Watch, Corporate Accountability International, Remunicipalisation Tracker

Fonte: Kishimoto et al. (2015, p. 17). 
Kishimoto et al. (2015) ressaltam que foram considerados apenas casos efetivos de remunicipalização, ou seja, situações as quais os serviços de água já haviam retomado para o domínio público. Apesar do mapeamento de Kishimoto et al. (2015) não incluir casos brasileiros, o Water Remunicipalisation Tracker destacou iniciativas de remunicipalização da água no Brasil (Bonecini-Almeida, 2019). Segundo dados do rastreador, no Brasil apenas dois estados apresentam casos de remunicipalização: São Paulo e Tocantins - que serão comentados posteriormente.

Mesmo com uma grande insatisfação nos serviços que são prestados pelas empresas privadas, nem sempre é por este motivo que o processo de remunicipalização é iniciado. Independentemente da diversidade dos casos, temos, acima de qualquer natureza do serviço, um bem que é destinado à população e que deve ser gerido com responsabilidade para garantir condições básicas de sobrevivência e qualidade de vida.

Em cidades da Espanha, por exemplo, March, Grau-Satorras, Saurí, e Swyngedouw (2019) destacam que o retorno dos serviços de água para domínio público ocorreu mediante justificativa de que a água, enquanto um recurso indispensável para a vida, deve ser administrada pelo setor público, resultando em melhores condições para os cidadãos, dentre elas a redução de tarifas (March et al., 2019).

McDonald (2015) chama a atenção aos desafios de adequar esses serviços para a realidade local, visto que, antes do domínio público, estiveram sob os moldes privados. Conforme apresentado pelo autor, eventual- mente os moldes de uma empresa privada permanecerão no domínio público dos serviços por muito tempo. Não se trata, exclusivamente, de uma mudança de propriedade (McDonald, 2015). Compreender o processo de gestão pública ou privada da prestação dos serviços para a sociedade é avaliar o desempenho, os impactos, os resultados e, sobretudo, o papel social.

Para Connor et al. (2019), "a existência de estruturas institucionais inclusivas designadas para o diálogo e a cooperação entre as múltiplas partes interessadas é essencial para garantir o acesso equitativo a serviços sustentáveis de abastecimento de água e saneamento" (p. 4). A administração pública tem hoje uma estrutura defasada, e as responsabilidades de fornecer serviços são de todos, não cabendo somente ao governo.

A água é um bem público, de interesse público e, no cenário da remunicipalização dos serviços, permeia uma nova possibilidade para o desenvolvimento de ideias coletivas (Lobina, 2015). Deste modo, as práticas entre a coprodução e os serviços no domínio público podem fortalecer as inter-relações entre a sociedade e o Estado, gerando responsabilidades compartilhadas.

\section{COPRODUÇÃO DO BEM PÚBLICO}

Há uma gama de perspectivas e tipologias de coprodução do bem público como: quem coproduz; quantas pessoas e em que estágio a coprodução ocorre; o que é coproduzido; e como a coprodução se relaciona com outras formas de participação cidadã (Durose, Needham, Mangan, \& Rees, 2017). Para compreender o contexto dessa temática, o artigo apresenta como o campo epistemoló- 
Érica Aline Ferreira Silva Yamamoto - José Roberto Pereira - Valderí de Castro Alcântara

gico da coprodução do bem público tem se constituído e quais mecanismos contribuem para o seu fortalecimento na contemporaneidade.

Segundo O'Brien, Offenhuber, Baldwin-Philippi, Sands, e Gordon (2017), as discussões sobre coprodução surgiram nos anos 1970 no Workshop in Political Theory and Policy Analysis, na Universidade de Indiana, com a apresentação do conceito pela autora Elinor Ostrom e seu grupo de trabalho como uma alternativa ao sistema burocrático e centralizador da administração pública. Nos anos de 1980, O'Brien et al. (2017) ressalta que a incorporação do público na prestação de serviços era pauta das discussões entre os autores da época, uma vez que reconheceram as possíveis melhorias que os cidadãos, enquanto parte do processo, proporcionariam aos serviços do governo (Whitaker, 1980; Parks et al., 1981).

Parks et al. (1981) apresentam a definição para o conceito de coprodução: "coproduction involves a mixing of the productive efforts of regular and consumer producers. This mixing may occur directly, involving coordinated efforts in the same production process, or indirectly through independent, yet related efforts of regular producers and consumer producers" (p. 1002). Para os autores, coprodução é um conjunto de atividades que conta com a colaboração tanto de servidores públicos como de cidadãos que, em uma junção de esforços, buscam melhorar a prestação de serviços. Esse mix, assim denominado por Parks et al. (1981), é apropriado apenas em situações em que a coprodução é tecnicamente viável e economicamente eficiente.
Segundo Parks et al. (1981), a coprodução também se direciona a um potencial de aumentar a eficiência e a eficácia de um governo local. Este propósito de eficiência e de eficácia veio em resposta às pressões fiscais da época e, em parte, devido à sensação de ineficácia das atividades no setor público. $O$ papel do cidadão na produção dos serviços recebeu atenção particular e, à medida que a sociedade se torna mais complexa, é comum a prática de indivíduos ou grupos produzirem bens e serviços em prol de um retorno, uma melhoria (Parks et al., 1981).

Na perspectiva de Ostrom (1996), a coprodução implica cidadãos que desempenham um papel ativo na produção de bens e serviços públicos. Este papel ativo é uma forma de sinergia entre ações praticadas pelos governos e ações desempenhadas pelos cidadãos. A partir de esforços complementares entre cidadão e setor público, a coprodução pode tornar os serviços mais eficientes e eficazes, assim como já havia afirmado no trabalho em parceria com Roger Parks e outros autores (Parks, et al., 1981; Ostrom, 1996).

Essas definições clássicas deram início ao debate de coprodução. Nos últimos anos, a compreensão do conceito evoluiu e assumiu um caráter multidisciplinar nas discussões práticas e acadêmicas (Brandsen \& Honingh, 2015). Paralelamente, os autores destacam que a coprodução cada vez mais é inserida na agenda de políticas visando ao interesse pela participação cidadã. Neste sentido, emerge o papel e a importância do cidadão, seja individual ou em grupo, na prestação de serviços (Brandsen \& Honingh, 2015).

O exercício da coprodução na formulação e implementação de políticas públicas é discu- 
tido por Bovaird (2007), Osborne, Radnor, e Strokosch (2016), dentre outros pesquisadores. Bovaird (2007) parte de uma reflexão a respeito do papel da formulação de políticas e da prestação de serviços no setor público. Essa visão, segundo o autor, contribui para um processo mais dinâmico e participativo de políticas públicas, no qual a formulação nem sempre ocorre de cima para baixo. Complementa-se, ainda, que os produtos não devem ser entregues "prontos" para os cidadãos, mas sim coproduzidos pelos usuários (Whitaker, 1980; Bovaird, 2007).

$\mathrm{Na}$ fase de implementação, Osborne e Strokosch (2013) afirmam que a coprodução na prática é moldada pela experiência de cada cidadão em uma determinada prestação de serviços, envolvendo as expectativas do indivíduo, seu papel ativo no processo e sua subsequente experiência no campo de atuação (Osborne \& Strokosch, 2013). Osborne et al. (2016) complementam que a coprodução é uma das temáticas centrais para a reforma das políticas públicas no mundo. Perante um cenário marcado pela reforma do serviço público, planejamento e prestação de serviços efetivos, os autores afirmam que a coprodução ainda é pouca trabalhada. É preciso promover discussões e conhecimentos sobre a temática em prol do desenvolvimento de formulação e implementação de políticas públicas.

Para que haja participação é necessário que se tenha também motivação para participar e estudos desenvolvidos por Alford (2002, 2009), Verschuere, Brandsen, e Pestoff (2012), Van Eijk e Steen (2014), O'Brien et al. (2017), dentre outros autores, abordam essa temática para a coprodução. Alford (2002) inicia sua reflexão indagando por que os indivíduos do setor público coproduzem. $\mathrm{O}$ autor faz esse questionamento no intuito de descobrir a motivação de cada um em coproduzir bens e serviços. Alford (2009) explora como as organizações governamentais precisam de cidadãos para contribuir com o tempo e o esforço, a fim de coproduzir serviços públicos. Além disso, o autor discorre sobre como as organizações podem alcançar melhor esse trabalho, fornecendo um bom atendimento ao indivíduo e atraindo suas necessidades intrínsecas e valores sociais (Alford, 2009).

Verschuere et al. (2012) compartilham do mesmo questionamento feito por Alford (2002). Os autores buscam compreender o que levam as pessoas a coproduzirem. Eles acreditam que os indivíduos são motivados pelos benefícios e ganhos que determinada ação irá resultar. Esta recompensa pode ser material, monetária ou até mesmo não monetária como um bairro mais seguro em troca de ser um membro da vigilância (Verschuere et al., 2012).

Segundo Verschuere et al. (2012), na coprodução os cidadãos contribuem deliberadamente com tempo e esforço na produção de serviços que antes eram de responsabilidade apenas de organizações e atores profissionais. Essa contribuição é uma escolha que advém da própria pessoa. Mas os autores fazem uma ressalva: quanto maior o esforço necessário para os cidadãos se envolverem, menor a probabilidade de que farão isso. Vale destacar que, além da motivação individual para coproduzir, outras circunstâncias podem facilitar e/ou dificultar a coprodução (Verschuere et al., 2012).

O’Brien et al. (2017) também discutem acer- 
ca da motivação que leva os cidadãos a participarem de programas que envolvem a coprodução de serviços governamentais. Para os autores, conhecer os fatores que desencadeiam em participação é relevante tanto para a formulação como para a implementação de programas, uma vez que bons resultados dependem do nível de participação cidadã (O'Brien et al., 2017).

Para Osborne e Strokosch (2013), a coprodução é uma importante vertente da atual agenda de reforma dos serviços públicos em todo o mundo. O'Brien et al. (2017) apresentam que nos últimos anos têm se intensificado os estudos sobre a coprodução, após um declínio de publicações nos anos 90 . Os autores reforçam que este renascimento teve forte contribuição da renovada interpretação da governança que busca agora ações voltadas às necessidades do público e não apenas um trabalho eficiente e eficaz. Este contexto contribui para a discussão dos fundamentos da coprodução de bens e serviços públicos no processo de remunicipalização. Becker, Naumann, e Moss (2017), por exemplo, desenvolveram um trabalho em perspectiva semelhante. Com base nos estudos de caso de Berlim e Hamburgo, na Alemanha, os autores analisaram a remunicipalização de serviços públicos com uma forte agenda democrática e ecológica voltada para a infraestrutura energética. Becker et al. (2017) procuraram maneiras de entender os tipos de desenvolvimento que transcendem os binários convencionais, como propriedade pública versus propriedade privada ou consumidor versus produtor.

Segundo Schommer e Moraes (2010), "no âmbito da sociedade civil, observam-se novas formas de ação coletiva, mudanças em características de movimentos sociais, novos tipos de associações e articulações destas com o Estado" (p. 308). Nessa conjuntura, o terceiro setor desempenha importante papel para a intermediação entre os anseios da sociedade e os serviços que são ofertados pelo Estado. Pestoff (2012) busca compreender o papel exercido pelo terceiro setor e a coprodução enquanto promoção do desenvolvimento, da renovação da democracia e do estado de bem-estar social. O autor aborda essa temática enfatizando a maior participação do cidadão na prestação de serviços públicos (Pestoff, 2012).

No contexto de relações mais próximas entre sociedade e Estado, a governança deliberativa depende de espaços públicos para o seu exercício, viabilizando o engajamento cívico do cidadão nos processos de implementação e decisões políticas (Freitas, Freitas, \& Dias, 2012). Dryzek (2000) afirma que a deliberação é um processo comunicativo para resolver questões políticas, tendo como finalidade a ação deliberativa que busca o bem comum. Habermas (2003) contribui ao dizer que "o processo da política deliberativa constitui o âmago do processo democrático" (p. 18).

Esses e outros estudos ampliam o conhecimento de coprodução e suas mais diversas áreas e aplicações. A seguir, este artigo aborda as perspectivas de gestão no cenário dos serviços de água e saneamento.

\section{PERSPECTIVAS DE GESTÃO DOS SERVI- ÇOS DE ÁGUA E SANEAMENTO}

Para ilustrar as relações entre remunicipalização e coprodução do bem público podemos utilizar a descrição dos casos de Itu, 
São Paulo, e do Estado do Tocantins, envolvendo 79 municípios. Em Itu, São Paulo, Bonecini-Almeida (2019) relata que há anos o município sofria com fraco desempenho por parte dos operadores privados, incluindo problemas de infraestrutura, atrasos de construções, falta de preparo para lidar com eventuais casos de racionamento de água, aumento de taxa e falta de transparência. Em 2017, o controle dos serviços de água e saneamento foi devolvido para o setor público com a criação de uma nova empresa pública, a Companhia Ituana de Saneamento ou Empresa de Saneamento de Itu.

Neste sentido, Bonecini-Almeida (2019) esclarece que é responsabilidade do setor público o planejamento, a execução, a operação e a recuperação de custos dos serviços de abastecimento de água e esgoto, limpeza urbana, gerenciamento de resíduos sólidos e outras atividades relacionadas. Atualmente, dentre os 5.570 municípios brasileiros, Itu ocupa o $111^{\circ}$ lugar em qualidade de serviços de água e sanitários (Bonecini-Almeida, 2019).

Diante das responsabilidades do setor público, a sociedade também tem o seu papel. Linders (2012) reforça essa questão ao afirmar que os cidadãos são reconhecidos como parceiros e não clientes na prestação de serviços públicos. Essa visão é de grande valor social nas relações entre quem oferta o serviço e quem recebe. No âmbito da gestão e dos serviços de abastecimento de água, observa-se que a nova configuração da sociedade e suas relações contribuem para um cenário institucional deliberativo, com exercício pleno do direito e da cidadania. Fato que pode ser fortalecido por meio do processo de remunicipalização.
No Estado do Tocantins, Bonecini-Almeida (2019) ressalta que 79 municípios encerraram a concessão privada devido ao fracasso dos sistemas privatizados de abastecimento de água potável, serviços de esgoto, saneamento e gestão e drenagem de resíduos sólidos. A empresa pública Agência Tocantinense de Saneamento foi criada e, dentre outras responsabilidades, cabe a ela instalar e manter sistemas de abastecimento de água e esgoto para clientes residenciais e comerciais, fornecer instalações, gerenciar contas e pagamentos por todos esses serviços (Bonecini-Almeida, 2019). Atualmente, Bonecini-Almeida (2019) destaca que a empresa pública fornece água para cerca de 400 mil pessoas nas zonas rurais dos 139 municípios do Tocantins e cerca de $250 \mathrm{mil}$ pessoas nas áreas urbanas de 79 municípios.

Com o fortalecimento do governo local, Frey (2004) trata da importância de compreender o campo da coprodução visto que há uma tendência de os próprios governos assumirem papel propulsor na ampliação da participação pública. Assim, este cenário demanda por abordagens capazes de integrar a dimensão governamental e as relações sociopolíticas. Jakobsen (2013) compartilha dessa inquietação ao analisar se as iniciativas do governo podem aumentar a coprodução das pessoas nos serviços públicos. Para o autor, é difícil medir as iniciativas governamentais na coprodução entre os cidadãos diante de um sistema voltado para decisões internas, no qual o indivíduo não tem muita abertura para atuação.

Por outro lado, a coprodução de bens e serviços pode constituir-se como resposta à 
escassez de recursos e de legitimidade governamentais (Rocha, Schommer, Debetir, \& Pinheiro, 2019).

Os governos podem ir além das exigências legais, promovendo transparência de atos, omissões, critérios, recursos, resultados, acertos, erros e suas justificativas. Isso proporciona conhecimento por parte da sociedade sobre a atuação do governo. Já a obtenção e o uso de informações e do conhecimento são elementos ativos da cidadania. Dependem do interesse e da ação dos cidadãos para conhecer a atuação e as justificações do governo e gerar consequências a partir disso (Rocha et al., 2019, p. 7).

Salm (2014) esclarece que a coprodução se realiza porque se deseja melhor atuação das organizações públicas, com maior participação de ONGs visando ao bem-estar da comunidade, ao interesse público e à promoção de cidadãos engajados para uma transformação social. O conhecimento de mecanismos e as ações em prol da coprodução contribuem para que a gestão pública faça jus às suas raízes sociais. Com o processo de remunicipalização, novas perspectivas permeiam o cenário para uma atuação conjunta entre governo e sociedade.

Para compreender melhor a aplicabilidade da temática coprodução, destaca-se que:
Entre os exemplos de coprodução, pode-se citar a discussão compartilhada ou o diálogo que se estabelece entre o aparato formal público e os integrantes de uma comunidade, visando definir políticas e diretrizes voltadas para o desenvolvimento sustentável de um território. Também são exemplos de coprodução a integração entre uma escola e a associação de pais e mestres dessa escola, na busca em comum de meIhorias para a educação dos alunos. Outro exemplo é a conjugação de esforços entre órgãos de segurança pública e comunidades, visando à segurança de um bairro ou área de um território (Salm, 2014, p. 43).

Os relatos apresentados por Salm (2014) sustentam as perspectivas levantadas por esse estudo, criando a possibilidade de analisar os processos de remunicipalização dos serviços de água e saneamento sob a ótica da coprodução do bem público.

Construímos a Figura 2 para ilustrar as aproximações entre a noção de remunicipalização e coprodução do bem público. No que se refere à remunicipalização destacam-se os elementos responsabilidade social, eficiência, sustentabilidade e controle social. Por sua vez, na coprodução do bem público tem-se participação, transparência, accountability e confiança, conforme as contribuições de Rocha et al. (2019). 
Figura 2. Remunicipalização e Coprodução do Bem Público.

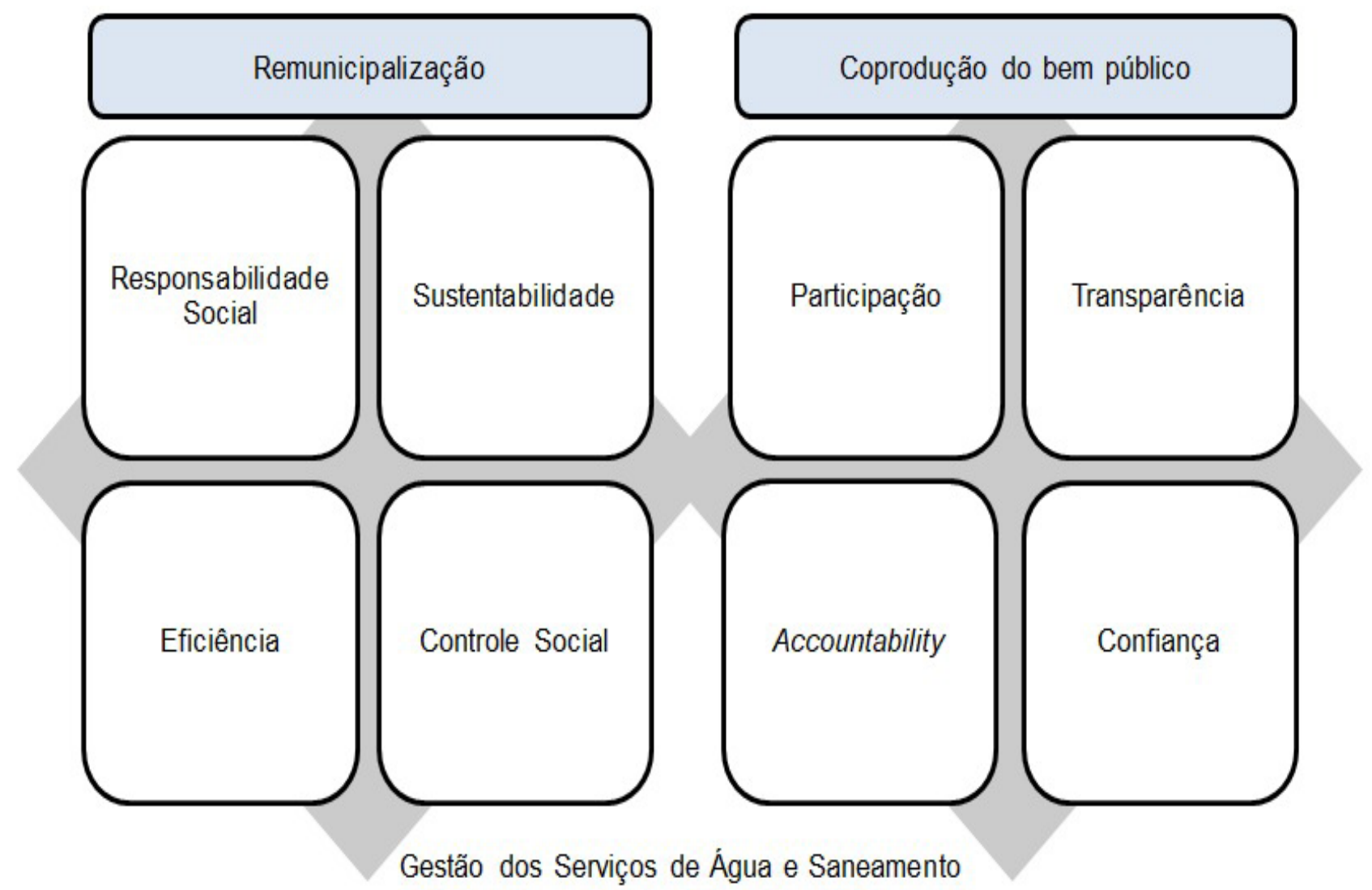

Na Figura 2, indicamos que existem aproximações entre os processos de remunicipalização e o desenvolvimento da coprodução do bem público, em especial, envolvendo a gestão dos serviços de água e saneamento destacados neste artigo. Rocha et al. (2019) relatam a importância de compreender os elementos transparência, accountability, confiança e participação que se inter-relacionam nos processos de coprodução. A coprodução requer responsabilização permanente dos gestores públicos, de forma transparente para que os cidadãos tenham ciência dos atos praticados. A reciprocidade entre cidadãos e governo é fundamental para que haja confiança, promovendo também a participação (Rocha et al., 2019). Todo esse processo é um continuum de ações e práticas que podem ocorrer no âmbito da gestão dos serviços de água e saneamento.

Schommer e Moraes (2010) complementam que, nas participações, os cidadãos exercitam cada vez mais o controle social e experimentam formas de coprodução do bem público.

Coprodução exige canais de expressão de diferentes interesses e perspectivas, intermediados pelo diálogo e pela construção de consensos e objetivos comuns, em processos permeados por conflitos, relações de poder e articulações negociadas entre os diferentes sujeitos em cena, os quais investem no processo seus conhecimen- 
Érica Aline Ferreira Silva Yamamoto - José Roberto Pereira - Valderí de Castro Alcântara

tos, recursos e capacidades (Schommer \& Moraes, 2010, p. 308).

Esses fatores reforçam a análise da remunicipalização sob as perspectivas de responsabilidade social e eficiência que tanto o município de Itu, como os 79 municípios do Estado do Tocantins buscaram com o processo de remunicipalização visando à sustentabilidade e ao controle social. Esses municípios passaram por mudanças administrativas e organizacionais frente às deficiências na operação das empresas privadas, com falta de transparência e diversos problemas que acarretaram ônus à população.

Ao observar a construção da Figura 2, percebemos que os princípios da remunicipalização são fortalecidos pelos elementos da coprodução do bem público, o que pode representar uma possibilidade para o seu desenvolvimento no âmbito abordado neste estudo. Agora, cidades e cidadãos estão se preparando para proteger e reinventar os serviços públicos (Kishimoto et al., 2015).

A seguir, apresentam-se as considerações finais e os direcionamentos de pesquisas futuras.

\section{CONSIDERAÇÕES FINAIS}

Mais do que uma mera mudança na provisão do serviço, a remunicipalização representa uma nova possibilidade para o desenvolvimento de ideias coletivas, como o direito humano à água e à sustentabilidade (Lobina, 2015). A questão, além de um agente provedor de serviços, envolve mudanças na oferta de oportunidades para a construção de ambientes sociais e sustentáveis. Remunicipalização é um recurso para construir alian- ças entre diversos atores sociais, incluindo a água pública (Lobina, 2015).

As tendências mundiais refletem um cenário de preocupação com a gestão das águas. No caso do Brasil, a água potável é distribuída e gerenciada por diferentes naturezas jurídicas. Com base em uma pesquisa desenvolvida pelo Instituto Mais Democracia, que investigou o mercado privado dos serviços de saneamento básico, Stiftung (2018) afirma que o setor é controlado por 26 empresas. Em 1996 foi fundada a Associação Brasileira das Concessionárias Privadas de Serviços Públicos de Água e Esgoto que reúne tanto as empresas privadas, como outras de ligação direta ou indireta com a cadeia produtiva do setor de saneamento básico. Além disso, são encontradas prestações de serviços no âmbito da administração pública direta, ou seja, ligados diretamente ao governo, e da administração pública indireta com uma estratégia mais descentralizadora.

As metas em cumprimento da agenda 2030 se articulam em prol da gestão integrada entre sociedade, Estado e mercado como forma de ampliar a cooperação e o apoio internacional aos programas relacionados à água e ao saneamento para que ninguém seja deixado para trás. A coprodução está vinculada a uma colaboração entre órgãos públicos e cidadãos, sejam eles individuais ou em grupo (Brandsen \& Honingh, 2015). De debate multidisciplinar, a coprodução no gerenciamento dos serviços de água no setor público pode obter êxito ao incorporar os diferentes elementos identificados na Figura 2.

Com a remunicipalização e a gestão da água nos municípios brasileiros, a coprodução sinaliza o elo da administração pública pro- 
vedora desse serviço e da população que deve prezar por este bem. Assim os cidadãos têm oportunidades de engajar-se, participar, compartilhar responsabilidades e cobrar do próprio setor melhores serviços. Como eles são os maiores interessados em uma prestação de serviços de qualidade, a prática da coprodução proporciona isso.

A partir dessa discussão, emergem premissas de pesquisa (agenda) que podem ser testadas empiricamente em estudos futuros. Essas premissas foram construídas com base na literatura consultada e são apresentadas na forma de proposições, quais sejam:

1) A remunicipalização de serviços de água e saneamento sinaliza para um novo desenho institucional sob a ótica da coprodução do bem público;

2) A coprodução do bem público pode fortalecer o movimento de remunicipalização;

3) A remunicipalização no Brasil apresenta dificuldades no processo de implementação devido à discrepância de repasses financeiros entre os entes federados;

4) O pacto federativo no Brasil contribuiu negativamente para o processo de remunicipalização;

5) A participação social e a corresponsabilidade presentes na teoria da coprodução do bem público fortalecem o domínio público dos serviços de água e saneamento.

Essas proposições de estudo podem mostrar como a remunicipalização potencializa o desenvolvimento da coprodução do bem público.

\section{REFERÊNCIAS}

Age, L. M., \& Schommer, P. C. (2017). Coprodução de Serviço de Vigilância Sanitária: Certificação e Classificação de Restaurantes. Revista de Administração Contemporânea, 21(3), 413-434. doi: 10.1590/19827849rac2017170026.

Alford, J. (2002). Why Do Public-Sector Clients Coproduce? Toward a Contingency Theory. Administration \& Society, 34(1), 3256. doi: 10.1177/0095399702034001004.

Alford, J. (2009). Engaging Public Sector Clients: From Service-Delivery to Co-Production. Basingstoke: Palgrave Macmillan, 261p. doi: 10.1057/9780230235816.

Batalden, M., Batalden, P., Margolis, P., Seid, M., Armstrong, G., Opipari-Arrigan, L., \& Hartung, H. (2016). Coproduction of healthcare servisse. BMJ Quality \& Safety, 25, 509-517. doi 10.1136/bmjqs-2015-004315.

Becker, S., Naumann, M., \& Moss, T. (2017). Between coproduction and commons: Understanding initiatives to reclaim urban energy provision in Berlin and Hamburg. Urban Research \& Practice, 10(1), 63-85. doi: 10.1080/17535069.2016.1156735.

Bonecini-Almeida, L. (2019). Water Remunicipalisation Tracker. Recuperado de http:// www.remunicipalisation.org/.

Bovaird, T. (2007) Beyond Engagement and Participation: User and Community Co-Production of Public Services. Public Administration Review, 67(5), 846-860. doi: 10.1111/j.1540-6210.2007.00773.x.

Brandsen, T., \& Honingh, M. (2015). Distinguishing Different Types of Coproduction: A 
Érica Aline Ferreira Silva Yamamoto - José Roberto Pereira - Valderí de Castro Alcântara

Conceptual Analysis Based on the Classical Definitions. Public Administration Review, 76(3), 427-435. doi: 10.1111/puar.12465.

Connor, R., Uhlenbrook, S., \& Koncagül, E. (2019). Relatório Mundial das Nações Unidas sobre Desenvolvimento dos Recursos Hídricos 2019: Não deixar ninguém para trás. Resumo Executivo. Recuperado de World Water Assessment Programme WWAP, UN-Water: https://unesdoc.unesco. org/ark:/48223/pf0000367303_por.

Dowbor, L., \& Rodrigues, A. M. E. (2017). Administração de bens comuns: Governança hídrica em disputa. In CASTRO, J. E. (Orgs.). Water politics and management: Findings from Africa, Asia, Europe and Latin America. WATERLAT GOBACIT Working Papers Thematic Area Series - TA3, 4(2). Recuperado de http://waterlat.org/WPapers/ WGWPVol4No2.pdf.

Dryzek, J. S. (2000). Deliberative democracy and beyond: Liberals, critics contestations. Oxford: Oxford University Press.

Durose, C., Needham, C., Mangan, C., \& Rees, J. (2017). Generating 'good enough' evidence for coproduction. Evidence and Policy, 13(1), 135-151. doi: 10.1332/174426 415X14440619792955.

Freitas, A. F., Freitas, A. F., \& Dias, M. M. (2012). O colegiado de desenvolvimento territorial no contexto da descentralização da gestão de políticas públicas. Revista de Administração Pública, 46, 1201-1223. doi: 10.1590/S0034-76122012000500002.

Frey, K. (2004). Governança interativa: Uma concepção para compreender a gestão pú- blica participativa? Política \& Sociedade, 5 , 119-138. Recuperado de https://periodicos. ufsc.br/index.php/politica/article/view/1982.

Habermas, J. (2003). Direito e Democracia: Entre facticidade e validade. (vol II). Rio de Janeiro, Tempo Brasileiro, 354p.

Hachfeld, D. (2008). The Remunicipalisation of Water - Some Reflections on the Cases of Potsdam and Grenoble. Artigo apresentado no The Public Alternatives to Privatisation, European Summer University of Attac, Saarbrücken. Recuperado de http://www.who-owns-the-world.org/wp/wp-content/uploads/2008/08/attac-summer-school-hachfeld. pdf.

Jakobsen, M. (2013). 'Can Government Initiatives Increase Citizen Coproduction? Results of a Randomized Field Experiment', Journal of Public Administration Research and Theory, 23(1), 27-54. doi: 10.2307/23321083.

Kishimoto, S., Lobina, E., \& Petitjean, O. (Eds.). (2015). Our public water future: The global experience with remunicipalisation. Recuperado de https://www.tni.org/en/publication/our-public-water-future.

Linders, D. (2012). From e-government to we-government: Defining a typology for citizen coproduction in the age of social media. Government Information Quarterly, 29(4), 446454. doi: 10.1016/j.giq.2012.06.003.

Lobina, E. (2015). Calling for progressive water policies. In Kishimoto, S., Lobina, E., \& Petitjean, O. (Eds.). Our public water future: The global experience with remunicipalisation (pp. 6-17). Recuperado de https://www. tni.org/en/publication/our-public-water-future. 
Lobina, E. Hall, D. (2013). List of water remunicipalisations worldwide - as of november 2013. Public Services International Research Unit (PSIRU). Recuperado de https:// www.psiru.org/sites/default/files/2013-W-Remunicipalisationswater.pdf.

March, H., Grau-Satorras, M., Saurí , D., \& Swyngedouw, E. (2019). The deadlock of metropolitan remunicipalisation of water services management in Barcelona. Water Alternatives, 12(2), 360-379. Recuperado de http://www.water-alternatives.org/index. php/alldoc/articles/vol12/v12issue3/531-a12-2-14/file.

Mcdonald, D. A. (2015). You are public... now what? News ways of measuring success. In Kishimoto, S., Lobina, E., \& Petitjean, O. (Eds.). Our public water future: The global experience with remunicipalisation (pp. 8695). Recuperado de https://www.tni.org/en/ publication/our-public-water-future.

O'Brien, D. T., Offenhuber, D., Baldwin-Philippi, J., Sands, M., \& Gordon, E. (2017). Uncharted Territoriality in Coproduction: The Motivations for 311 Reporting. Journal of Public Administration Research and Theory, 27(2), 320-335. doi: 10.1093/jopart/ muw046.

Organização Das Nações Unidas (ONU). (2010). Água potável: Direito humano fundamental. Nova York. Recuperado de https:// nacoesunidas.org/agua-potavel-direito-humano-fundamental/.

Organização Das Nações Unidas (ONU). (2015). Transformando Nosso Mundo: a agenda 2030 para o desenvolvimento sus- tentável. Nova York. Recuperado de https:// nacoesunidas.org/pos2015/agenda2030/.

Osborne, S. P., Radnor, Z., \& Strokosch, K. (2016). Co-Production and the Co-Creation of Value in Public Services: A suitable case for treatment? Public Management Review, 16, 639-653. doi: 10.1080/14719037.2015.1111927.

Osborne, S., \& Strokosch, K. (2013). It Takes Two To Tango? Understanding the Co-Production of Public Services by Integrating the Services Management and Public Administration Perspectives. British Journal of Management. doi: 10.1111/1467-8551.12010.

Ostrom, E. (1996). Crossing the great divide: Coproduction, synergy, and development. World Development, 24(6), 1073-1087. doi: 10.1016/0305-750X(96)00023-X.

Parks, R. B., Baker, P. C., Kiser, L., Oakerson, R., Ostrom, E., Ostrom, V., ... Wilson, R. (1981). Consumers as Coproducers of Public Services: Some Economic and Institutional Considerations. Policy Studies Journal, 9(7), 1001-1011. doi: 10.1111/j.15410072.1981.tb01208.x.

Pestoff, V. (2012). Co-production and Third Sector Social Services in Europe: Some Concepts and Evidence. Voluntas: International Journal of Voluntary and Nonprofit Organizations, 23(4), 1102-1118. doi: 10.1007/ s11266-012-9308-7.

Piccoli, A. De S., Kligerman, D. C., Cohen, S. C., \& Assumpção, R. F. (2016). A Educação Ambiental como estratégia de mobilização social para o enfrentamento da escassez de água. Ciência \& Saúde Co- 
letiva, 21(3), 797-808. doi: 10.1590/141381232015213.26852015 .

Rocha, A. C., Schommer, P. C., Debetir, E., \& Pinheiro, D. M. (2019). Transparência como Elemento da Coprodução na Pavimentação de Vias Públicas. Cadernos Gestão Pública e Cidadania, 24(78). doi: 10.12660/cgpc. v24n78.74929.

Salm, J. F. (2014). Coprodução de bens e serviços públicos. In Boullosa, R. F. (Org.). Dicionário para a formação em gestão social (pp. 42-44). Salvador, BA: CIAGS/UFBA.

Schommer, P. C., \& Moraes, R. L. (2010). Observatórios Sociais como Promotores de Controle Social e Accountability: reflexões a partir da experiência do observatório social de Itajaí. Gestão.Org Revista Eletrônica de Gestão Organizacional, 3(8), 298-326. Recuperado de https://periodicos.ufpe.br/revistas/gestaoorg/article/view/21657.

Stiftung, H. B. (2018). Quem são os proprietários do saneamento no Brasil? Rio de Janeiro. Recuperado de https://br.boell.org/ pt-br/2018/06/25/quem-sao-os-proprieta- rios-do-saneamento-no-brasil.

Van Eijk, C.J., \& Steen, T.P. (2014). Why people co-produce:Analysing citizens' perceptions on co-planning engagement in health care services. Public Management Review, 3(16), 358382. doi: 10.1080/14719037.2013.841458.

Verschuere, B., Brandsen, T., \& Pestoff, V. (2012). Co-Production: The State of the Art in Research and the Future Agenda. Voluntas: International Journal of Voluntary and Nonprofit Organizations, 4(23), 1083-1101. doi: 10.1007/s11266-012-9307-8.

Whitaker, G. (1980). Co-Production: Citizen Participation in Service Delivery. Public Administration Review, 40(3), 240-246. doi: 10.2307/975377.

World Health Organization (WHO), \& The United Nations Children's Fund (UNICEF). (2017). Progress on Drinking Water, Sanitation and Hygiene. Recuperado de https://www. who.int/mediacentre/news/releases/2017/ launch-version-report-jmp-water-sanitation-hygiene.pdf.

Agradecemos à FAPEMIG - Fundação de Amparo à Pesquisa do Estado de Minas Gerais. 